Research Article

\title{
Study on Seismic Reliability of UHVDC Transmission Systems
}

\author{
Kun Yao $(\mathbb{D})$ and Jiang Qian $(1)$ \\ State Key Laboratory of Disaster Reduction in Civil Engineering, Tongji University, Shanghai 200092, China \\ Correspondence should be addressed to Jiang Qian; jqian@tongji.edu.cn
}

Received 6 March 2019; Revised 1 May 2019; Accepted 26 May 2019; Published 10 June 2019

Academic Editor: Hamid Toopchi-Nezhad

Copyright (c) 2019 Kun Yao and Jiang Qian. This is an open access article distributed under the Creative Commons Attribution License, which permits unrestricted use, distribution, and reproduction in any medium, provided the original work is properly cited.

\begin{abstract}
Electric power system is critical to maintain the welfare of the general public with impact on economic losses and other cascading. In this paper, the seismic reliability of the ultra-high-voltage direct current (UHVDC) transmission system was evaluated from a perspective of the subsystem fault logic. An assessment model of system seismic reliability was proposed based on the state enumeration method. A case study was presented by taking a typical $800 \mathrm{kV}$ UHVDC transmission system as the example. The finite element models of major components in the UHVDC transmission system were established to evaluate their seismic reliability. The results reveal that though the seismic reliability of major components seems satisfactory overall, the UHVDC transmission system may still suffer from seismic hazards to a certain degree due to the complexity of the full system. This calls for a further enhancement in seismic design requirements of the electrical equipment.
\end{abstract}

\section{Introduction}

Utility deregulation, distributed power generation, wind farms, solar parks, and smart grid visions are constantly changing the facade of modern power system [1]. Ultra-highvoltage direct current technology has characteristics, which makes it especially attractive for certain transmission applications such as long-distance bulk-power delivery, asynchronous interconnections, and long submarine cable crossings [2]. These applications can bring great benefits for operation security and economy of the whole power system. Since 1972, the installed capacity of high-voltage direct current (HVDC) projects has reached over 200000 megawatts and continues to grow, with ratings of 7500 megawatts and $\pm 800 \mathrm{kV}$ on a single bipolar system [3]. With the continuous development of UHVDC transmission technology and the increasing number of actual engineering, the reliability of UHVDC transmission system has become an important factor affecting the reliability of the entire power system [4].

In the past, considerable work has been done in reliability evaluation of HVDC transmissions. Based on the technique of failure modes and effects, Kuruganty [5] proposed a reliability evaluation model of HVDC transmission by using a frequency and duration approach.
Dialynas et al. [6] proposed a hybrid method based on a Monte Carlo simulation sequential approach for the overall reliability assessment of autonomous power systems incorporating HVDC interconnection links. ContrerasJiménez et al. [2] presented a reliability analysis method based on the matrix-based system reliability method, which is a competitive alternative in terms of simplicity and efficiency. UHVDC transmission systems have complicated configuration and complex operation modes, which give rise to the technical difficulties in dealing with the reliability evaluation. Based on the subdivision of the system, Xie et al. [4] proposed a reliability evaluation model for the more complicated UHVDC transmission system. However, those works are mainly based on the system abundance analysis, that is, the ability of the system to meet the system load demand under the specified operational requirements without considering large disturbances during disasters such as earthquake.

Functionality of electric power systems is critical to maintain the welfare of the general public, to sustain the economic activities, and to assist the recovery, restoration, and reconstruction of the seismically damaged environment [7]. Past earthquakes, however, have highlighted the vulnerability of such systems with impact on economic losses 
and other cascading effects [8]. In light of the above, seismic reliability evaluation of UHVDC transmission systems is an essential process in the planning of UHV power systems.

UHV transmission technology is developing rapidly in the seismically active regions including China, as backbone power grids are being built out over long distances [9]. However, so far little information on the seismic performance of UHV electrical equipment is available since most of them was constructed in recent years. UHV electrical equipment is substantially larger than the high-voltage (HV) one and has different structural features. Substantial efforts have been given to the seismic performance of electrical equipment based on numerical simulation and laboratory experiments [10-14]. However, most of them are still mainly focusing on the individual equipment itself, and very little attention has been payed to the seismic reliability of the whole system.

In order to study the seismic reliability of the whole system, the UHVDC transmission system is divided into different subsystems and the fault logic between each subsystem is analysed. Based on the expectation of transmission capacity after earthquake, the system seismic reliability assessment model is established by a state enumeration method. The case study was carried out taking an UHVDC transmission system for example. The seismic reliability of the system and the impact of the seismic reliability of each device on the system are studied.

\section{Seismic Reliability Evaluation Models for UHVDC Transmission}

The concept of seismic reliability is extremely broad, including all aspects of the system seismic resilience. In this paper, reliability is used as a general term describing the residual ability of the system to perform its function after earthquake. As UHVDC transmission systems are mainly used for long-distance, high-power transmission, for the system abundance analysis, the reliability index is generally defined from the perspective of transmission capacity and expressed as forced outage time every year, like monopole forced outage time and bipole forced outage times [15]. However, earthquakes are accidental disasters that may occur once in decades. Obviously, the indexes used in abundance analysis are not suitable in seismic reliability analysis. Consequently, the expectation of the residual transmission capacity after earthquake (ERTC) is proposed as a seismic reliability indicator. Earthquakes reduce the transmission capacity of the power system by destroying the equipment. In this paper, the seismic reliability of UHVDC transmissions is evaluated from the perspective of structural safety of the equipment.

2.1. Subdivision of the System. UHVDC transmission systems have complicated configuration and flexible operation modes, which are commonly two-terminal and bipolar systems with 2 sets of serial 12-pulse converter valve groups in each pole. A typical $\pm 800 \mathrm{kV}$ UHVDC transmission system is shown in Figure 1. Each set of converter valve group (accounting for $1 / 4$ rated capacity) can be disconnected by the switches so each pole can achieve partial operation. UHVDC transmission systems have 5 operating modes: the normal state, the partial monopole outage, the monopole outage, the partial bipole outage, and the bipole outage. Complexity gives rise to the technical difficulties in dealing with the reliability evaluation. Although any practical and complex system can be analysed as one entity using the event tree method, the most efficient method of analysis is to subdivide the system into modules. Each module may contain a various number of individual components.

The UHVDC transmission system is divided into 3 subsystems based on the impact of equipment failure on the transmission capacity. This method offers several advantages, including the complete independence of modules in analysis and the significant decrease of the computational effort.

2.1.1. Converter Transformer and Valves (CTV) Subsystem. This subsystem mainly consists of a 12-pulse converter valves group and transformers connected to it. The 12-pulse converter valves group is composed of 3 quadruple valves. UHVDC transmission projects basically adopt singlephasedouble-winding converter transformer (CT) and each 12-pulse converter valves group is connected with $3 \mathrm{Y} /$ $\mathrm{Y} C T$ s and $3 \mathrm{Y} / \Delta \mathrm{CTs}$. Failure of any quadruple valve or converter transformer will cause the subsystem shutdown.

2.1.2. Direct Current (DC) Subsystem. This subsystem mainly consists of smoothing reactors, direct current filters, and transmission lines. There is one group of DC filters at each pole and UHV smoothing reactors are usually arranged, respectively, on the neutral bus and the pole bus. According to the investigation of historical earthquake damage, the seismic reliability of transmission line is much higher than that of equipment, so the vulnerability of transmission line is ignored in this paper.

2.1.3. Alternate Current Filter (ACF) Subsystem. This subsystem mainly consists of AC filters. Different AC filters are divided into groups and installed in towers. The towers are made of pillar insulators and channel steel beams. The number and type of AC filters in operation will influence transmission capacity of the system.

Besides the equipment described above, there are also a variety of secondary or auxiliary equipment, including station control system, pole control system, and auxiliary power supply system. Thanks to its beneficial structural features, the secondary or auxiliary equipment usually has a high seismic reliability and does not directly affect transmission capacity, and thus will not be discussed in this paper. The reliability logic relationships among subsystems are shown in Figure 2.

The two converter stations of the UHV transmission system are often more than several thousand kilometres apart. The possibility of simultaneous earthquakes at both converter stations is negligible. It is assumed that the 


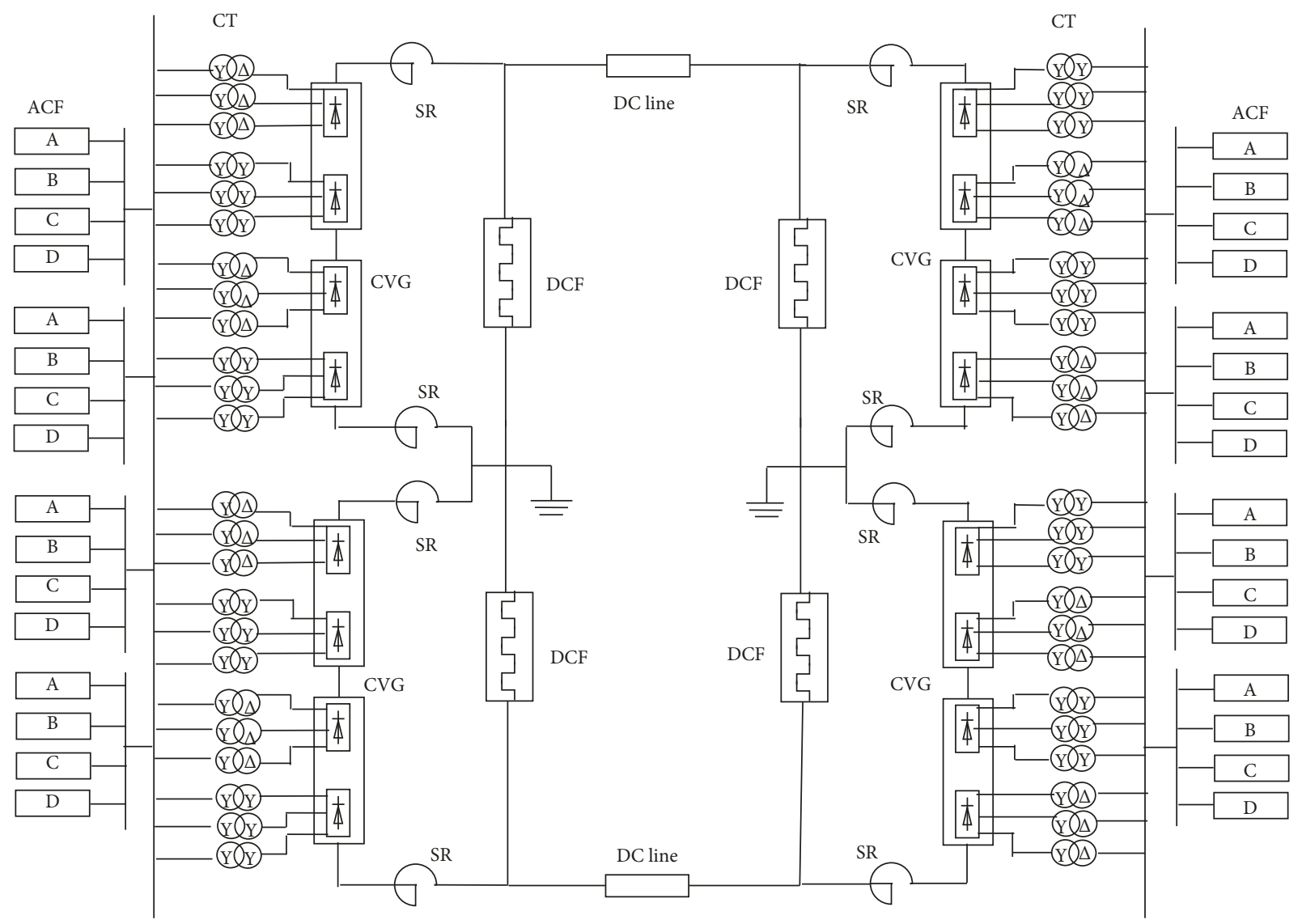

Figure 1: Schematic diagram of main electrical connection of UHVDC transmission. ACFs represent the AC filters; CTs represent the converter transformers; CVGs represent the 12-pulse converter valves groups; SRs represent the smoothing reactors; DCFs represent DC filters; and DC lines represent the DC transmission lines.

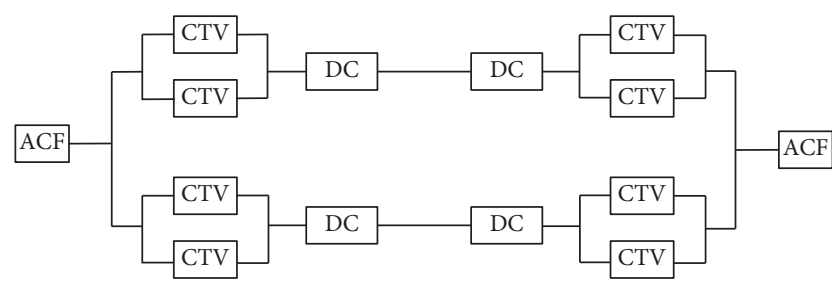

Figure 2: Logic schematic of UHVDC transmission system.

opposite station is in good operating condition when an earthquake occurs at a converter station. Consequently, the reliability logic relationships can be further simplified, shown in Figure 3.

2.2. Seismic Reliability Evaluation of Equipment. The subsystems are series-parallel combination of devices. There are three main research methods for seismic vulnerability of electrical equipment: statistical analysis of previous seismic damage data, seismic performance test, and numerical simulation [16]. Statistical data based on historical seismic hazard are the most realistic. However, UHVDC transmission systems have a short history and have not been tested by earthquakes. The size of UHV electrical equipment is much larger than that of traditional $\mathrm{HV}$ electrical

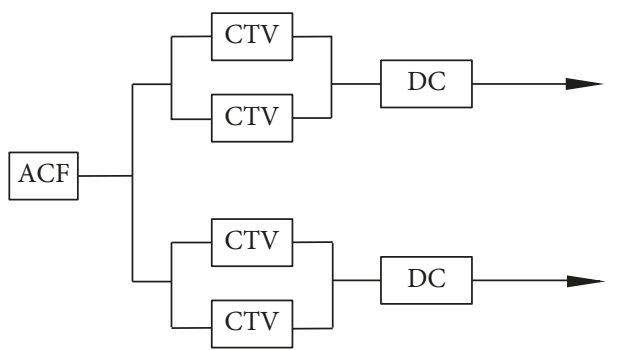

FIGURE 3: Equivalent block diagram of the UHVDC transmission system.

equipment, so the historical seismic damage data of $\mathrm{HV}$ equipment are not practical for the UHV equipment. UHV electrical equipment is often huge and expensive. Because of economic or technical constraints, shaking table tests of prototype equipment are very few. Therefore, this paper adopts the numerical simulation method to study the reliability of electrical equipment.

Electrical equipment usually undergoes brittle failure. Its limit state equation is linear, so first-order second moment method can meet the accuracy requirement for seismic reliability evaluation [17]. The seismic resistance and response of the equipment are subject to normal distribution. The seismic reliability index is calculated as follows: 


$$
\begin{aligned}
& \beta=\frac{\mu_{\mathrm{R}}-\mu_{\mathrm{S}}}{\sqrt{\sigma_{\mathrm{R}}^{2}+\sigma_{\mathrm{S}}^{2}}}, \\
& P=\phi(\beta),
\end{aligned}
$$

where $\beta$ is the seismic reliability index; $\phi(\cdot)$ is the standard normal distribution function; $\mu_{\mathrm{R}}$ and $\sigma_{\mathrm{R}}$ are expectation and variance of structural resistance respectively; $\mu_{\mathrm{S}}$ and $\sigma_{\mathrm{S}}$ are expectation and variance of maximum seismic response; and $P$ is the seismic reliability of the equipment. Li et al. [18] have proposed a method to calculate the expectation and standard deviation of the maximum seismic response of electrical equipment based on mode-superposition response spectrum method and finite element method.

$$
\begin{gathered}
\mu_{\mathrm{S}}=\sqrt{\sum_{i=1}^{m} S_{i}^{2},} \\
\sigma_{\mathrm{S}}=q \sqrt{\sum_{i=1}^{m} \frac{S_{i}^{2}}{p_{i}^{2}}},
\end{gathered}
$$

where $S_{i}$ is the expectation of the maximum seismic response of the $i^{\text {th }}$ mode of the equipment, which can be calculated by finite element method. $q$ is the process variance factor and $p_{i}$ is the mode peak factor, which can be calculated by the following formulas.

$$
\begin{aligned}
q & =\frac{\pi}{\sqrt{12 \ln \left(\left(\gamma_{2} / \pi\right) T_{\mathrm{d}}\right)}} \\
p_{i} & =\sqrt{2 \ln \left(\frac{\gamma_{2}}{\pi} T_{\mathrm{d}}\right)}+\frac{0.5772}{\sqrt{2 \ln \left(\left(\gamma_{2} / \pi\right) T_{\mathrm{d}}\right)}},
\end{aligned}
$$

where $T_{\mathrm{d}}$ is the strong earthquake duration and $\gamma_{2}$ is the power spectrum moment of inertia which can be estimated by the following formula for broadband input.

$$
\frac{\gamma_{2}}{\pi} \approx \frac{\omega_{i}}{\pi}
$$

where $\omega_{i}$ is the angular frequency of each mode.

2.3. Seismic Reliability Evaluation of the Subsystem. The seismic reliability data of the equipment should be processed to obtain the seismic reliability of the subsystems. The function of the equipment in the CTV and DC subsystem is in series because any failure of component can lead to the subsystem shutdown, that is, the subsystem can only run when every component is intact. According to the main wiring diagram of the important equipment of the UHVDC transmission system in Figure 2, the seismic reliability of the CTV and DC subsystem can be obtained, as shown in equations (6) and (7).

$$
\begin{gathered}
P_{\mathrm{CTV}}=P_{\mathrm{V}}^{n_{\mathrm{v}}} P_{\mathrm{T}}^{n_{\mathrm{T}}}, \\
P_{\mathrm{DC}}=P_{\mathrm{S}}^{n_{\mathrm{S}}} P_{\mathrm{F}}^{n_{\mathrm{D}}},
\end{gathered}
$$

where $P_{\mathrm{CTV}}$ and $P_{\mathrm{DC}}$ are the seismic reliability of the CTV and DC, respectively; $P_{\mathrm{V}}, P_{\mathrm{T}}, P_{\mathrm{F}}$, and $P_{\mathrm{S}}$ are the seismic reliability of the converter valves, converter transformers, direct current filters, and smoothing reactors, respectively; $n_{\mathrm{V}}$ and $n_{\mathrm{T}}$ are the number of converter valves and converter transformers in the CTV, respectively; and $n_{\mathrm{S}}$ and $n_{\mathrm{D}}$ are the number of smoothing reactors and direct current filters in the DC, respectively.

Generally, the number and type of the filters in operation are different for different operating modes. Operating strategy table of ACFs, which is called Capacity State Table (CST) of filters, illustrates the impact of the number and type of AC filters on the available transmission capacity [4]. The filters are placed in groups in the tower supported by post insulators. In earthquakes, the failure of filters is often caused by the drop of components caused by the damage of load-bearing structures and, therefore, the filters are damaged in group. The available capacity of the state of the ACF subsystem should be considered according to the specific situation. Different damage conditions may result in the same subsystem capacity and, therefore, the probability of the ACF subsystem under certain capacity is the sum of probabilities of all conditions. The probability of the ACF subsystem of different capacity states can be calculated as equation (8).

$$
P_{\mathrm{A}_{i}}=\sum C_{n_{\mathrm{F}}}^{m_{\mathrm{F}}} P_{\mathrm{F}}^{m_{\mathrm{F}}}\left(1-P_{\mathrm{F}}\right)^{\left(n_{\mathrm{F}}-m_{\mathrm{F}}\right)},
$$

where $P_{\mathrm{A}_{i}}$ is the probability of different capacity states of the ACF subsystem after earthquake; $n_{\mathrm{F}}$ is the number of filter groups in the ACF subsystem of one condition; $m_{\mathrm{F}}$ is the number of intact filter group of the particular capacity state of the ACF subsystem; and $P_{\mathrm{F}}$ is the seismic reliability of the filter group based on the structural safety of the bearing insulator tower.

\subsection{Seismic Reliability Evaluation Model of the System.} The failure effects of each subsystem on the system seismic reliability are illustrated in Figure 3. The CTV and DC failures affect the operating state of the pole to which they are connected, while ACF simultaneously affects two poles. Subsystems can be classified into monopolar subsystem (CTV and DC) and bipolar subsystem (ACF) based on their sphere of influence. Based on the reliability logic diagram and the seismic reliability evaluation results of each subsystem, the reliability evaluation of an UHVDC transmission system can be done by the state enumeration method.

Firstly, the system transmission capacity reduction caused by the failures of monopolar subsystems are analysed and listed in Table 1.

The residual transmission capacity of the system is determined by both monopolar subsystems and bipolar subsystems. Different states of monopolar subsystems and bipolar subsystems may result in the same system postearthquake capacity and, therefore, the probability of the system under certain capacity is the sum of probabilities of all combinations. Expectation of transmission capacity after system earthquake can be calculated as follows: 
TABLE 1: Seismic reliability calculation of monopole subsystem.

\begin{tabular}{|c|c|c|}
\hline Post-earthquake capacity & Monopolar subsystem condition & Calculation formula \\
\hline $100 \%$ & All is well & $P_{\mathrm{CVT}}^{4} P_{\mathrm{DC}}^{2}$ \\
\hline $75 \%$ & Only one CTV fails & $C_{4}^{1}\left(1-P_{\mathrm{CVT}}\right) P_{\mathrm{CVT}}^{3} P_{\mathrm{DC}}^{2}$ \\
\hline $50 \%$ & $\begin{array}{c}\text { Only one DC fails and the CTVs connected with } \\
\text { the runnable DC are well } \\
\text { Both DCs are well, but } 2 \text { CTVs fail }\end{array}$ & $\begin{array}{c}C_{1}^{2} P_{\mathrm{DC}}\left(1-P_{\mathrm{DC}}\right) P_{\mathrm{CVT}}^{2} \\
C_{4}^{2} P_{\mathrm{CVT}}^{2}\left(1-P_{\mathrm{CVT}}\right)^{2} P_{\mathrm{DC}}^{2}\end{array}$ \\
\hline $25 \%$ & $\begin{array}{l}\text { Only one DC fails and one of the CTVs } \\
\text { connected with the runnable DC fails } \\
\text { Both DCs are well and } 3 \text { CTVs fail }\end{array}$ & $\begin{array}{c}C_{2}^{1} C_{2}^{1} P_{\mathrm{DC}}\left(1-P_{\mathrm{DC}}\right) P_{\mathrm{CVT}}\left(1-P_{\mathrm{CVT}}\right) \\
C_{4}^{3}\left(1-P_{\mathrm{CVT}}\right)^{3} P_{\mathrm{CVT}} P_{\mathrm{DC}}^{2}\end{array}$ \\
\hline $0 \%$ & $\begin{array}{l}\text { Both DCs fails } \\
\text { Only one DC fails and the two CTVs } \\
\text { connected with the runnable DC fail } \\
\text { Both DCs are well and CTVs fail }\end{array}$ & $\begin{array}{c}\left(1-P_{\mathrm{DC}}\right) \\
C_{2}^{1} P_{\mathrm{DC}}\left(1-P_{\mathrm{DC}}\right)\left(1-P_{\mathrm{CVT}}\right)^{2} \\
P_{\mathrm{DC}}^{2}\left(1-P_{\mathrm{CVT}}\right)^{4}\end{array}$ \\
\hline
\end{tabular}

$C_{n}^{k}$ represents the number of combinations.

$$
\begin{gathered}
W_{\text {sys }}=W_{\mathrm{mo}} W_{\mathrm{A}}, \\
P_{\text {sys }_{i}}=\sum P_{\mathrm{mo}_{j}} P_{\mathrm{A}_{k}}, \\
E\left(W_{\text {sys }}\right)=\sum_{i=1}^{n} W_{\text {sys }_{i}} P_{\text {sys }_{i}},
\end{gathered}
$$

where $W_{\text {sys }}$ is the residual transmission capacity of the system after the earthquake. $P_{\text {sys }_{i}}$ is the probability of different transmission capacity of the system after earthquake. (After the earthquake, the transmission capacity of the system may become $100 \%, 75 \%, 50 \%, 37.5 \%, 25 \%, 12.5 \%$, or $0 \%$.) $P_{\text {mo }}$ and $P_{\mathrm{A}_{k}}$, respectively, represent the probability of the capacity of the monopolar system and the ACF subsystem in a corresponding combination. $E\left(W_{\text {sys }}\right)$ represents the expectation of residual transmission capacity after earthquake.

\subsection{Seismic Reliability Evaluation Algorithm for the UHVDC} Transmission System. Based on the idea of system division and seismic reliability evaluation models of major subsystems discussed above, the seismic reliability evaluation algorithm for UHVDC transmission systems can be summarized as follows:

Input the information of the configuration, the structural parameters of the important equipment, and the earthquake fortification intensity

Build the finite element model of the equipment and evaluate the seismic reliability of the important equipment

Evaluate the seismic reliability of the CTV and DC subsystems

Evaluate the seismic reliability of the ACF subsystems according to the specific situation

Calculate the reliability indices of the whole UHVDC transmission system using the state enumeration method

\section{Case Study}

A $\pm 800 \mathrm{kV}$ UHVDC transmission project is used as an example for case study, whose main electrical connection has been shown in Figure 1. This system has 48 converter transformers, 32 AC filters, 8 sets of 12-pulse converter valves, and 8 smoothing reactors. UHV converter stations are generally designed in accordance with the 8 seismic fortification in China and the seismic reliability is evaluated under 8 fortification intensity.

3.1. Reliability Calculation of Electrical Equipment. The finite element models are established for the important equipment in the UHVDC transmission system, and the maximum seismic responses of each mode are calculated by spectrum analysis. The seismic reliability of the equipment was evaluated by the method proposed by Li et al. [18] briefly introduced in Section 2.2. The seismic response spectrum refers to Chinese code [19]. Earthquake response spectrum is shown in Figure 4.

The seismic response spectrum curve is shown in equation (12), where $\alpha$ is the earthquake affecting coefficient; $\alpha_{\max }$ is the maximum earthquake affecting coefficient, which is 0.5 for 8 seismic fortification; $T_{\mathrm{g}}$ is the characteristic site period; $T$ is the free vibration period of structure; $\gamma$ is the damped exponential; and $\eta_{1}$ and $\eta_{2}$ represent the falling slope adjustment factor for straight line segments and the damping adjustment coefficient, respectively.

$$
\alpha= \begin{cases}{\left[0.40+\frac{\eta_{2}-0.40}{0.1} T\right] \alpha_{\max },} & 0 \leq T<0.1, \\ \eta_{2} \alpha_{\max }, & 0.1 \leq T<T_{\mathrm{g}}, \\ \left(\frac{T_{\mathrm{g}}}{T}\right)^{\gamma} \eta_{2} \alpha_{\max }, & T_{\mathrm{g}} \leq T<5 T_{\mathrm{g}}, \\ {\left[\eta_{2} 0.2^{\gamma}-\eta_{1}\left(T-5 T_{\mathrm{g}}\right)\right] \alpha_{\max },} & 5 T_{\mathrm{g}} \leq T \leq 6.0 .\end{cases}
$$

Seismic damage statistics and shaking table tests indicate that the porcelain bushings of the power equipment are the most vulnerable part because of poor deformability. The maximum seismic response of the high-voltage electrical equipment generally occurs at the bottom of the porcelain bushing [20]. In this paper the seismic reliability 


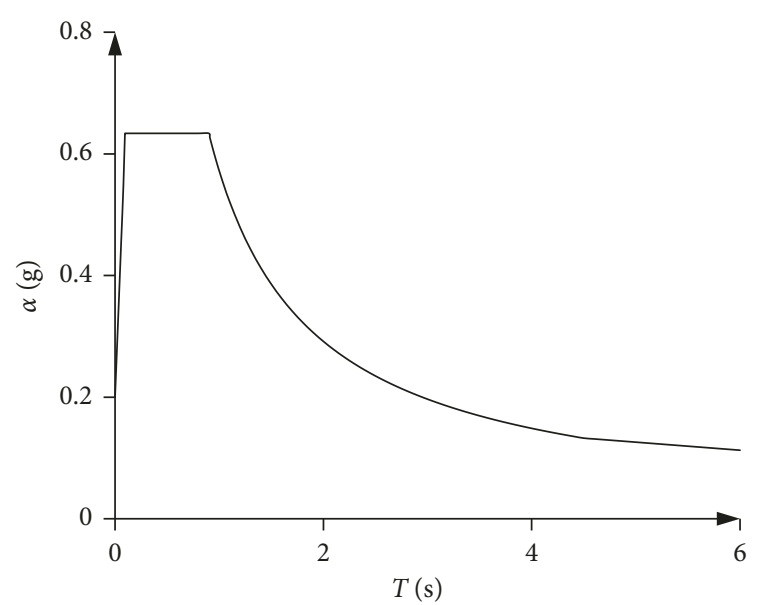

Figure 4: Seismic response spectrum curve.

of the equipment was evaluated based on the maximum stress of the bushings. The first 20 vibration modes are taken into consideration in the calculation of maximum stress response.

3.1.1. Converter Transformer. The UHV converter transformer tank is constructed from welded steel plates, and channel sections stiffen the steel plates out-of-plane. The transformer tank is $10 \mathrm{~m}$ long, $4.4 \mathrm{~m}$ wide, and $4.8 \mathrm{~m}$ high. The thickness of the plates that form the roof, sidewalls, and base of the transformer tank is $30 \mathrm{~mm}, 15 \mathrm{~mm}$, and $45 \mathrm{~mm}$, respectively. The turrets are fabricated using tubular steel sections with top and bottom flange plates that are bolted to the bushing flange and tank, respectively. The thickness of the tubes is $6 \mathrm{~mm}$. The turret attached on the roof of the tank is $1.44 \mathrm{~m}$ long and the turrets attached to the side wall are $6.15 \mathrm{~m}$ long. The elastic modulus of these steel plates and tubes is $210 \mathrm{GPa}$. The top bushing is $5.44 \mathrm{~m}$ long and the bushings attached to the sidewall are $10.52 \mathrm{~m}$. The external diameter and thickness of bushings are $560 \mathrm{~mm}$ and $50 \mathrm{~mm}$, respectively. The elastic modulus of porcelain bushings is $100 \mathrm{GPa}$. The iron cores and copper coils in the transformer tank are supported on an internal steel frame which is directly bolted to the baseplate of the tank. They contribute little to the overall stiffness of the UHV converter box. In order to simplify the computational analysis, the iron cores and copper coils are not considered in the finite element model. The contained oil is modelled as a kind of solid with an equivalent bulk modulus equal to that of the fluid since the transformer is fully filled with oil, and no sloshing effect may occur. The total weight of the finite element model is $68216 \mathrm{~kg}$. The transformer tank wall is simulated by shell element. The stiffening channel steel and bushings are simulated by beam element. The first 3 order frequencies of the structure are $0.953 \mathrm{~Hz}, 1.509 \mathrm{~Hz}$, and $1.748 \mathrm{~Hz}$, respectively. Due to the large rigidity of the main body of the transformer tank, the deformation of low-order modes is mainly generated by the bending of the bushing and bushing riser. The physical and finite element models of the UHV converter transformer are shown in Figure 5.
3.1.2. Converter Valves. UHV converter quadruple valves are mainly composed of valve modules, shield covers, and suspension support structures. The total height of the equipment is $13.3 \mathrm{~m}$. In the horizontal direction, the equipment is $4.3 \mathrm{~m}$ long and $4.1 \mathrm{~m}$ wide. The suspension insulators are made of epoxy composite material with a diameter of $24 \mathrm{~mm}$ and the valve modules are supported by aluminium alloy beam with a thickness of $6 \mathrm{~mm}$. The epoxy material has an elastic modulus of $23 \mathrm{GPa}$ and a density of $1900 \mathrm{~kg} / \mathrm{m}^{3}$. The elastic modulus of the aluminium alloy is $70 \mathrm{GPa}$. The total weight of equipment is $12480 \mathrm{~kg}$. The suspension insulators are slender and hinged to the valve hall and the top shield. They are simulated by a cable element. Aluminium alloy bearing frames are simulated by beam element. The structural assembly diagram and finite element model of the UHV quadruple converter valve are shown in Figure 6 . The fundamental frequency of the suspension structure is low. The first three frequencies of the structure are $0.153 \mathrm{~Hz}, 0.154 \mathrm{~Hz}$, and $0.157 \mathrm{~Hz}$, respectively. The first two modes are horizontal translation and the third mode is torsion. Considering the magnification effect of the valve hall, the peak acceleration of the input ground motion is doubled.

3.1.3. Smoothing Reactor. The UHV smoothing reactor is vertically supported by 12 high-strength porcelain insulator columns. The column height is $10.5 \mathrm{~m}$, consisting of 5 insulators. The column insulators are fixed with metal ribs in each layer. The diameter of the equipment is $4.5 \mathrm{~m}$. Its installation height is $15.1 \mathrm{~m}$. The elastic modulus of the porcelain insulator is $110 \mathrm{GPa}$. The total weight of the equipment is $83426 \mathrm{~kg}$. The supporting structure is simulated by beam element, and solid element is used to simulate the external contour and equivalent mass of the device. The first 3 frequencies of the structure are $1.229 \mathrm{~Hz}, 1.250 \mathrm{~Hz}$ and $2.442 \mathrm{~Hz}$. The first two modes are horizontal translation and the third mode is torsion. The physical and finite element models of the UHV dry type smoothing reactor are shown in Figure 7.

3.1.4. Filter. The UHV filter is composed of capacitors, inductors and resistors. These electrical components are placed in the tower supported by post insulators. In earthquakes, the failure of filters is often caused by the drop of components caused by the damage of load-bearing structures. The UHV filter tower is $23.8 \mathrm{~m}$ high, $3.6 \mathrm{~m}$ wide and $3.6 \mathrm{~m}$ long. The total weight is about $60012 \mathrm{~kg}$. The supporting structure is simulated by beam element. The physical and finite element models of the UHV filter are shown in Figure 8. The first 3 frequencies of the structure are $1.306 \mathrm{~Hz}, 1.342 \mathrm{~Hz}$, and $1.703 \mathrm{~Hz}$. The first two modes are translation. The third mode is torsion.

3.2. Seismic Reliability Analysis of the Subsystem. According to the antilateral force data of the high-strength porcelain electrical equipment of the Chinese Academy of Electric Power, the average value of the high-strength 


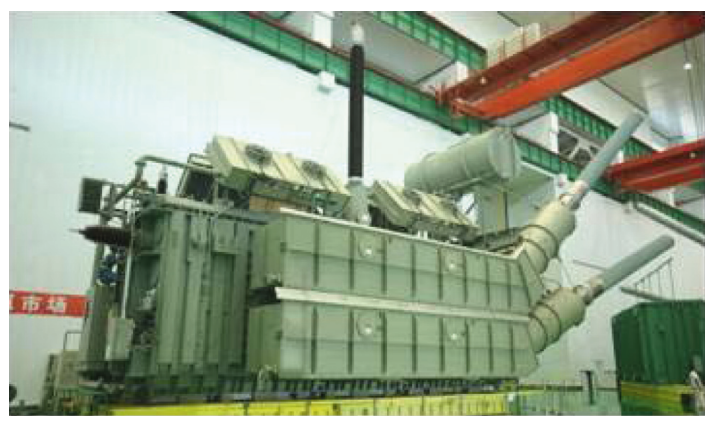

(a)

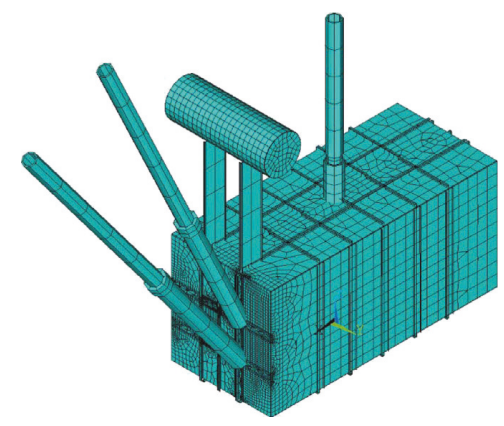

(b)

FIgURE 5: UHV converter transformer. (a) Site scene of the equipment and (b) finite element model.

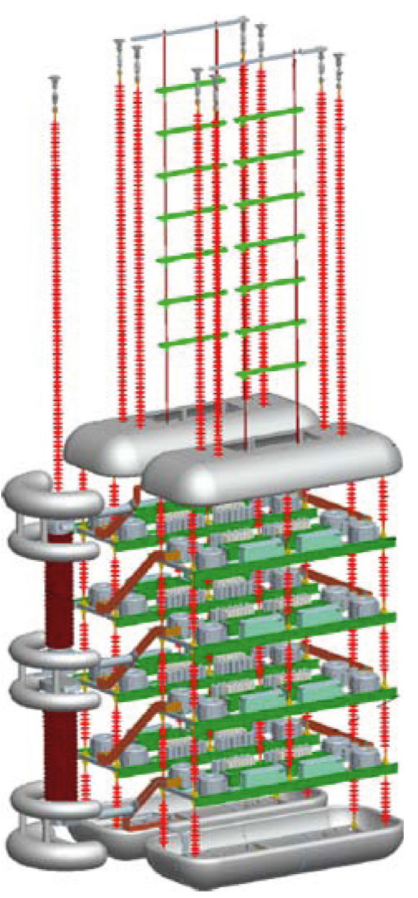

(a)

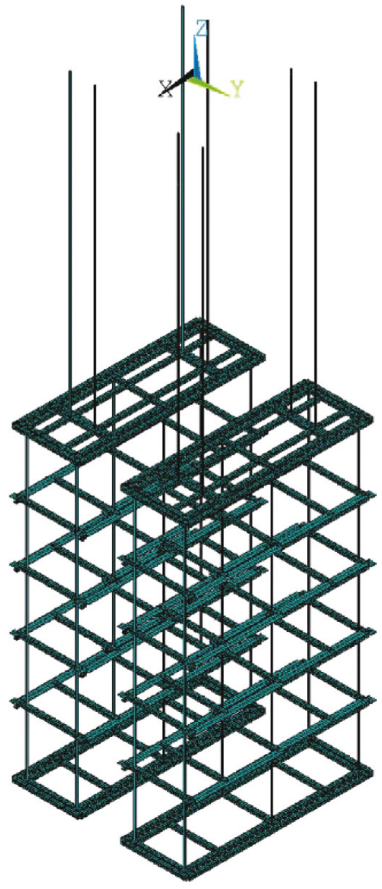

(b)
FIgURE 6: UHV converter quadruple valve. (a) Structural assembly drawing and (b) finite element model.

porcelain failure stress is $45 \mathrm{MPa}$ and the variance is $6 \mathrm{MPa}$ [17]. The average breaking stress of the epoxy composite insulator is $200 \mathrm{MPa}$, the dispersion coefficient of the epoxy material is about $6 \%$, and the variance is $12 \mathrm{MPa}$ [21].

Expectation and variance of the maximum stress response of insulators of each equipment under 8-degree fortification intensity were calculated. The reliability index was obtained by introducing data into formulas (1) and (2). The calculation results are listed in Table 2.

Based on equations (6) and (7), the seismic reliability of the single-pole subsystem can be obtained, as shown in Table 3. The UHVDC transmission system shown in Figure 1 is equipped with four sets of AC filters. Considering its capacity state table, the ACF subsystem has 3 capacity states, that is, if one or two filters failed, the system could be automatically adjusted by the control system without affecting the power transmission capacity; if three sets of filters failed at the same time, the transmission capacity would be reduced by $50 \%$; and if four sets of filters failed at the same time, the AC field subsystem would stop running. The probability of the transmission capacity of the AC field subsystem after the earthquake was obtained, as shown in Table 4.

The probability of different transmission capacity after earthquake of the UHVDC transmission system was obtained taking the calculation results of Tables 3 and 4 into the formulas (9) and (10). The expectation of the residual transmission capacity of this system can be obtained with formula (11). Seismic reliability means the probability that the transmission capacity of the system after the earthquake is not less than a certain value. It was calculated by adding all the possibilities of the failure modes whose residual transmission capacities are bigger than the certain value. The results are listed in Table 5.

3.3. Sensitivity to Equipment Reliability. The contribution of each device to system reliability depends on its location in the system topology and the size of its own parameters, which is referred to as the system sensitivity to equipment reliability [22]. The changes of the expectation of the transmission capacity after earthquake with the seismic reliability of equipment were calculated and the results are shown in Figure 9. The seismic reliability of the UHV converter valve, transformer, smoothing reactor, and filter changes from 0.998 to 0.850 , respectively. It can be clearly seen that the UHV converter transformer and the UHV converter valve have greater influence on the system reliability than others.

\section{Summary}

In this paper, the seismic reliability evaluation model of UHVDC transmission is proposed based on the system subdivision and the state enumeration method. Case studies of a $\pm 800 \mathrm{kV}$ UHVDC transmission project were conducted to show its applicability. Critical parts of the UHVDC transmission system were recognized by sensitivity analysis. Based on the computational results, the following conclusions can be made. 


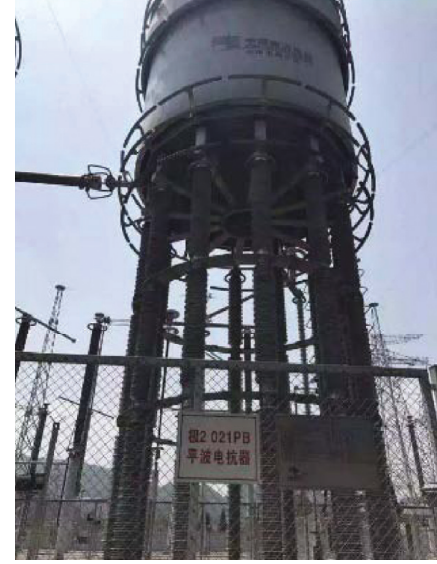

(a)

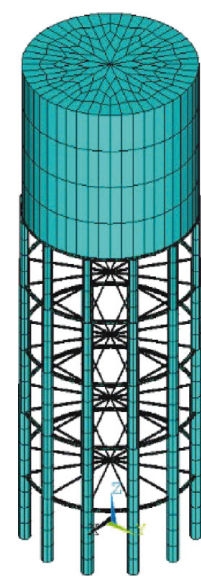

(b)
FIGURE 7: UHV smoothing reactor. (a) Site scene of the equipment and (b) finite element model.

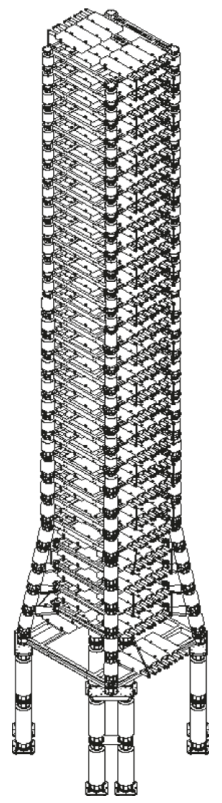

(a)

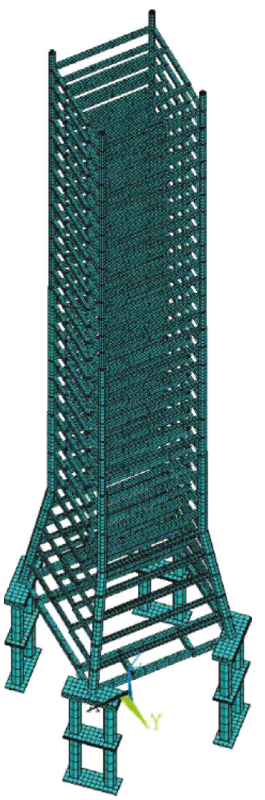

(b)
FIGURE 8: UHV filter tower. (a) Structural assembly drawing and (b) finite element model.

(1) Among the most important UHV electrical equipment considered in this paper, converter transformer and converter valve have greater impact on system reliability than the others. Fortunately, the seismic reliability of the UHV converter transformer is high because of its low centre of gravity and large stiffness; the UHV converter valve also has high seismic reliability because of the suspension seismic reduction design.

(2) The seismic reliabilities of the UHV smoothing reactor and UHV filter are relatively low and need to be strengthened. The use of the seismic mitigation and/ or absorption technology might be feasible measures for the UHV equipment supported by insulators.
TABLE 2: Seismic reliability of important electrical equipment.

\begin{tabular}{lcccc}
\hline Equipment & $\begin{array}{c}\text { Expectation } \\
(\mathrm{MPa})\end{array}$ & $\begin{array}{c}\text { Variance } \\
(\mathrm{MPa})\end{array}$ & $\begin{array}{c}\text { Reliability } \\
\text { index }\end{array}$ & $\begin{array}{c}\text { Seismic } \\
\text { reliability } \\
(\%)\end{array}$ \\
\hline Valve & 22.5 & 1.5 & 14.68 & 99.99 \\
Transformer & 21.3 & 5.5 & 2.91 & 99.98 \\
Reactor & 28.5 & 12.5 & 1.19 & 88.30 \\
smoothing & 23.1 & 12.3 & 1.60 & 94.52 \\
\hline
\end{tabular}

TABLE 3: Seismic reliability of a monopolar subsystem of the UHVDC transmission system.

\begin{tabular}{lcccc}
\hline Subsystem & Equipment & Quantity & Formula & $\begin{array}{c}\text { Seismic } \\
\text { reliability (\%) }\end{array}$ \\
\hline CTV & $\begin{array}{c}\text { Valve } \\
\text { Transformer }\end{array}$ & 3 & $P_{\mathrm{V}}^{3} P_{\mathrm{T}}^{6}$ & 99.85 \\
\hline \multirow{2}{*}{ DC } & $\begin{array}{c}\text { Reactor } \\
\text { smoothing }\end{array}$ & 2 & $P_{\mathrm{S}}^{2} P_{\mathrm{F}}$ & 73.70 \\
& Filter tower & 1 & & \\
\hline
\end{tabular}

Note: "Quantity" refers to the number of such devices in a single subsystem. The derivation of the formula is detailed in Section 2.3.

TABle 4: Seismic reliability of the AC field subsystem of the UHVDC transmission system.

\begin{tabular}{lccc}
\hline $\begin{array}{l}\text { Transmission } \\
\text { capacity }\end{array}$ & $\begin{array}{l}\text { Damage } \\
\text { quantity }\end{array}$ & Formula & $\begin{array}{c}\text { Seismic } \\
\text { reliability } \\
(\%)\end{array}$ \\
\hline $100 \%$ & $\leq 2$ & $\begin{array}{r}P_{\mathrm{F}}^{4}+C_{4}^{1} P_{\mathrm{F}}^{3}\left(1-P_{\mathrm{F}}\right) \\
+C_{4}^{2} P_{\mathrm{F}}^{2}\left(1-P_{\mathrm{F}}\right)^{2}\end{array}$ & 99.94 \\
$50 \%$ & 3 & $C_{4}^{3}\left(1-P_{\mathrm{F}}\right)^{3} P_{\mathrm{F}}$ & 0.062 \\
$0 \%$ & 4 & $\left(1-P_{\mathrm{F}}\right)$ & 0.001 \\
\hline
\end{tabular}

Note: "Damage quantity" refers to the number of filter towers damaged by the earthquake in the AC field subsystem and is judged from the perspective of structural safety. The derivation of the formula is detailed in Section 2.3.

TABLE 5: Reliability of different transmission capacity of a UHVDC transmission system after earthquake.

\begin{tabular}{lccc}
\hline $\begin{array}{l}\text { Transmission } \\
\text { capacity }\end{array}$ & $\begin{array}{c}\text { Reliability } \\
(\%)\end{array}$ & $\begin{array}{c}\text { Transmission } \\
\text { capacity }\end{array}$ & $\begin{array}{c}\text { Reliability } \\
(\%)\end{array}$ \\
\hline 0 & 100 & $50 \%$ & 92.929 \\
$12.5 \%$ & 93.071 & $75 \%$ & 54.270 \\
$25 \%$ & 93.069 & $100 \%$ & 53.951 \\
$37.5 \%$ & 92.930 & Expectation & 73.56 \\
\hline
\end{tabular}

Note: "Expectation" refers to the expectation of the residual transmission capacity after earthquake. The calculation process is detailed in Section 2.4.

(3) The reliability of electrical equipment designed according to current seismic codes seems satisfactory under seismic fortification intensity. However, due to the complexity of the UHVDC transmission system, potential safety hazards may not be eliminated completely for the system. The probability of maintaining the original transmission capacity unchanged after the earthquake is only $54.08 \%$, and the expectation of the transmission capacity after the earthquake is $73.61 \%$ of the original transmission 


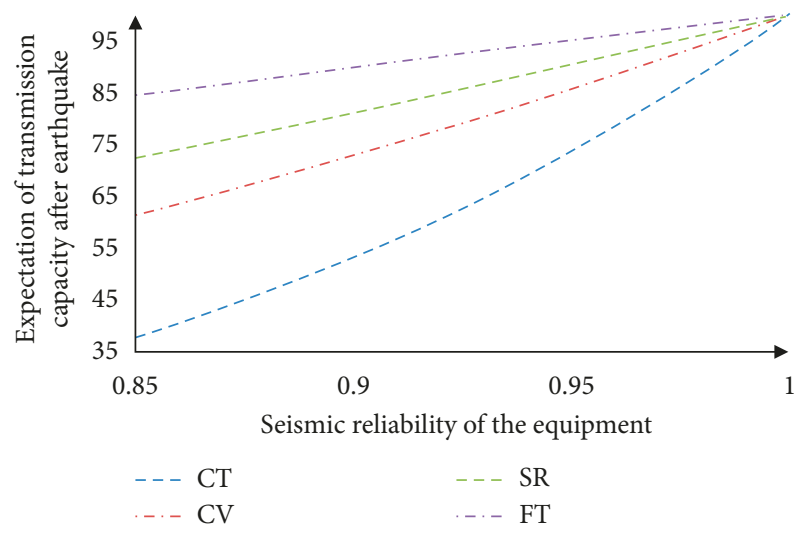

FIGURE 9: Impact of equipment reliability on overall system reliability.

capacity. Therefore, a further improvement to the seismic design requirements of the electrical equipment is expected.

\section{Data Availability}

The data used to support the findings of this study are available from the corresponding author upon request.

\section{Conflicts of Interest}

The authors declare that they have no conflicts of interest.

\section{Acknowledgments}

The authors acknowledge with thanks the support from the Ministry of Science and Technology of China through the Research Grant under No. SLDRCE19-B-28. Financial supports from the National Science Foundation of China (Grant no. 51638012) are also gratefully acknowledged.

\section{References}

[1] A. Kalair, N. Abas, and N. Khan, "Comparative study of HVAC and HVDC transmission systems," Renewable and Sustainable Energy Reviews, vol. 59, pp. 1653-1675, 2016.

[2] J. S. Contreras-Jiménez, F. Rivas-Dávalos, J. Song, and J. L. Guardado, "Multi-state system reliability analysis of HVDC transmission systems using matrix-based system reliability method," International Journal of Electrical Power \& Energy Systems, vol. 100, pp. 265-278, 2018.

[3] D. Kell, "HVDC to grow rapidly," Natural Gas \& Electricity, vol. 31, no. 10, pp. 11-18, 2015.

[4] K. Xie, B. Hu, and C. Singh, "Reliability evaluation of double 12-pulse ultra HVDC transmission systems," IEEE Transactions on Power Delivery, vol. 31, no. 1, pp. 210-218, 2016.

[5] S. Kuruganty, "Effect of HVDC component enhancement on the overall system reliability performance," IEEE Transactions on Power Delivery, vol. 9, no. 1, pp. 343-351, 1994.

[6] E. N. Dialynas, N. C. Koskolos, and D. Agoris, "Reliability assessment of autonomous power systems incorporating HVDC interconnection links," IEEE Transactions on Power Delivery, vol. 11, no. 1, pp. 519-525, 1996.
[7] M. A. Saadeghvaziri, B. Feizi, L. Kempner Jr, and D. Alston, "On seismic response of substation equipment and application of base isolation to transformers," IEEE Transactions on Power Delivery, vol. 25, no. 1, pp. 177-186, 2010.

[8] J. Wang, K. Dai, Y. Yin, and S. Tesfamariam, "Seismic performance-based design and risk analysis of thermal power plant building with consideration of vertical and mass irregularities," Engineering Structures, vol. 164, pp. 141-154, 2018.

[9] G.-L. Ma, Q. Xie, and A. Whittaker, "Seismic performance assessment of an ultra-high voltage power transformer," Earthquake Spectra, vol. 35, no. 1, pp. 423-445, 2019.

[10] G.-L. Ma, Q. Xie, and A. S. Whittaker, "Physical and numerical simulations of the seismic response of a $1,100 \mathrm{kV}$ power transformer bushing," Earthquake Spectra, vol. 34, no. 3, pp. 1515-1541, 2018.

[11] Z. Yang, Q. Xie, C. He et al., "Seismic response analysis of $\pm 800 \mathrm{kV}$ UHVDC converter valves," Proceeding of the CSEE, vol. 36, no. 7, pp. 1836-1841, 2016, in Chinese.

[12] S. L. Fan, J. Y. Chen, and J. Li, "Experimental study on seismic behavior of UHV dry-type smoothing reactor," Journal of Vibration Engineering, vol. 26, no. 2, pp. 226-231, 2013, in Chinese.

[13] C. He, Q. Xie, Z. Yang et al., "Analysis on seismic performance of $\pm 800 \mathrm{kV}$ UHVDC filter capacitor," Southern Power System Technology, vol. 11, no. 5, pp. 9-16, 2017, in Chinese.

[14] L. Luo, N. Jiang, and J. Bi, "Analysis of the effects of soil on the seismic energy responses of an equipment-structure system via substructure shaking table testing," Shock and Vibration, vol. 2019, 11 pages, 2019.

[15] S. Committee, IEEE Guide for the Evaluation of the Reliability of Hvdc Converter Stations, IEEE, Piscataway, NJ, USA, 2000.

[16] M. P. Xiong, Study on Vulnerability of Substation High Voltage Electrical Equipment Based on Different Ground Motion Parameters, Institute of Engineering Mechanics, Langfang, China, 2016.

[17] M. Zhong, Y. F. Cheng, Z. B. Dai, and Z. G. Fang, "Study on grading seismic fortification standards of electrical equipment at transformer substation," China Earthquake Engineering, vol. 37, no. 2, pp. 571-576, 2015, in Chinese.

[18] H. Chen and L. Li, "Seismic reliability analysis of high-voltage transformer," China Earthquake Engineering, vol. 16, no. 2, pp. 19-23, 2006, in Chinese.

[19] Ministry of Housing and Urban-Rural Development of China, GB50260-2013 Code for Seismic Design of Electrical Installations, Ministry of Housing and Urban-Rural Development of China, Beijing, China, 2013, in Chinese.

[20] L. Li, Z. Y. Cheng, K. Wu et al., "Seismic reliability analysis of high-voltage substation system," Journal of Huazhong University of Science and Technology (Natural Science Edition), vol. 39, no. 10, pp. 108-112, 2011, in Chinese.

[21] L. Zhang, Q. Sun, H. C. Wang et al., "Experimental study on the mechanical properties of E-glass fiber epoxy composite material," Electric Power Construction, vol. 31, no. 9, pp. 118-121, 2010, in Chinese.

[22] Y. Zhao, N. C. Zhou, K. G. Xie et al., "Sensitivity analysis on reliability assessment of bulk power system," Power System Technology, vol. 29, no. 24, pp. 25-30, 2005, in Chinese. 


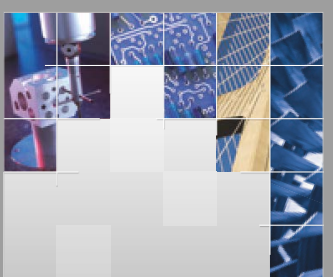

\section{Enfincering}
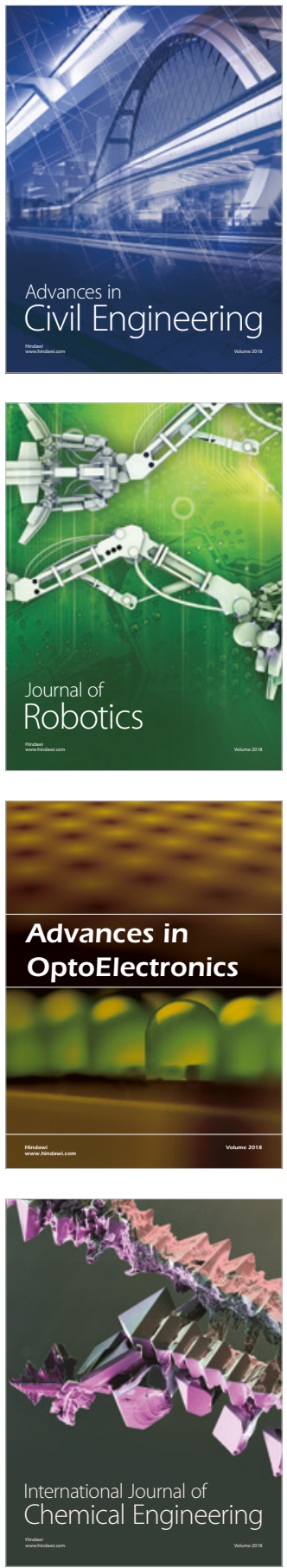

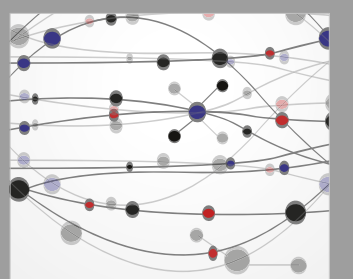

\section{Rotating \\ Machinery}

The Scientific World Journal

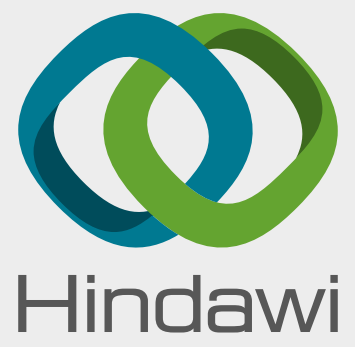

Submit your manuscripts at

www.hindawi.com
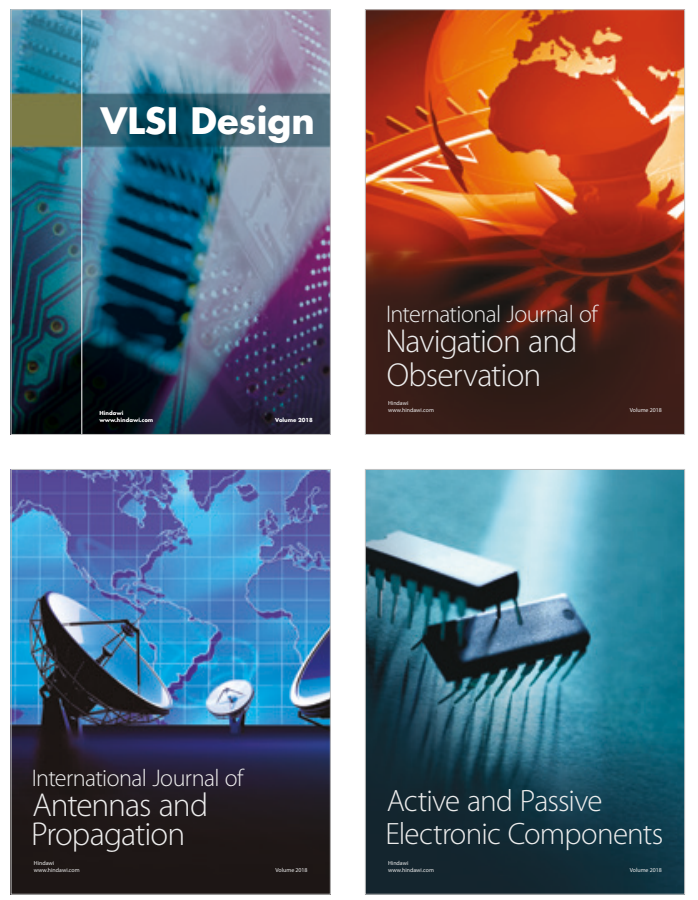
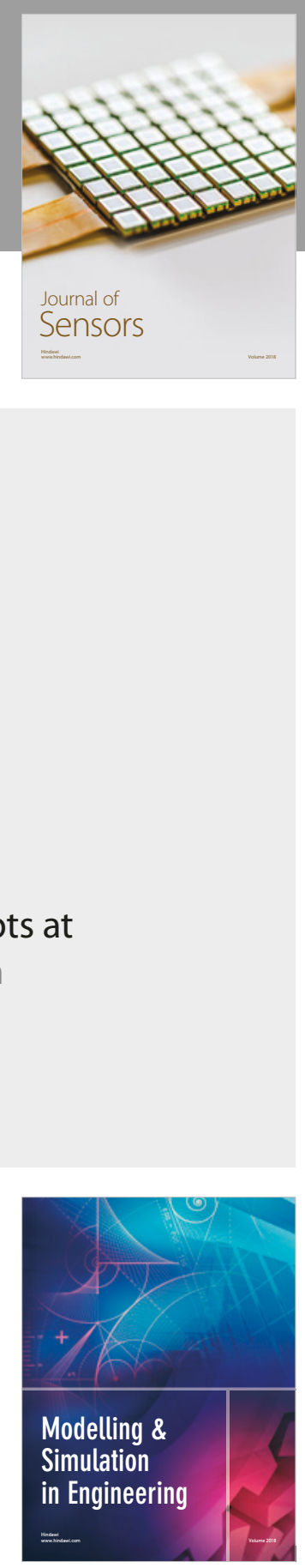

\section{Advances \\ Multimedia}
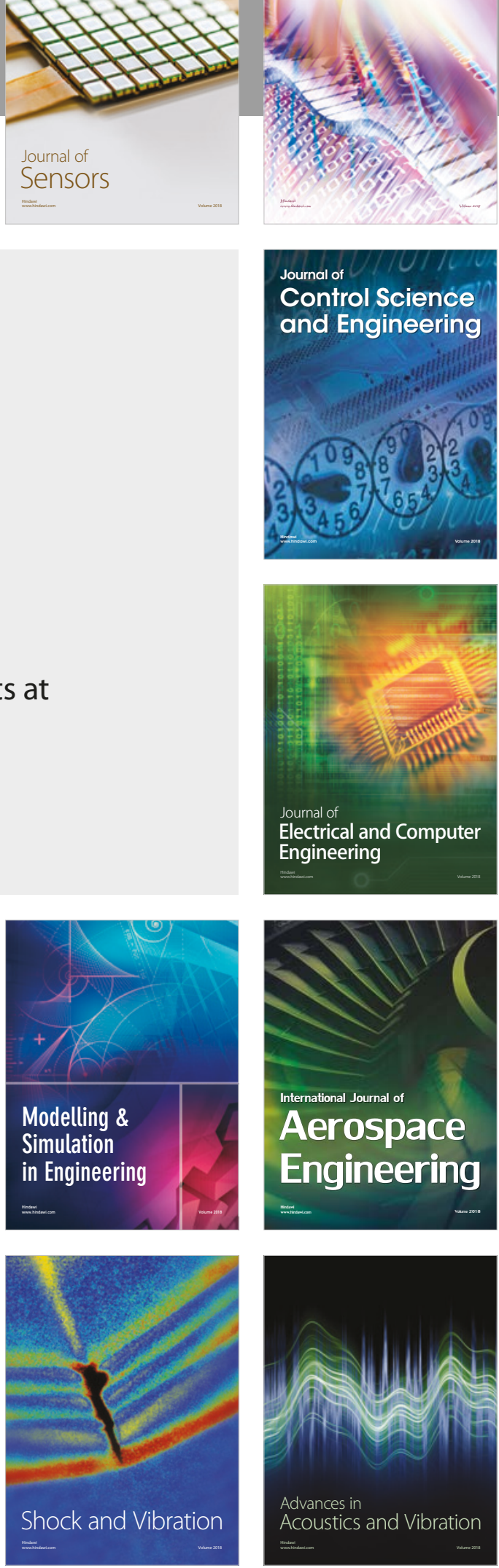